\title{
A Multiscale Structural Analysis of Soft and Hard Coal Deposits in Deep High-Gas Coal Seams
}

\author{
Anying Yuan $\left(\mathbb{D},{ }^{1}\right.$ Guangsheng $\mathrm{Fu}^{2}{ }^{2}$ and Junling $\mathrm{Hou}^{1,3}$ \\ ${ }^{1}$ State Key Laboratory of Mining-Induced Response and Disaster Prevention and Control in Deep Coal Mines, \\ Anhui University of Science and Technology, Huainan, Anhui 232001, China \\ ${ }^{2}$ Shandong Bureau of China Metallurgical Geology Bureau, Qingdao 266109, China \\ ${ }^{3}$ Panzhihua University, Panzhihua 617000, China \\ Correspondence should be addressed to Anying Yuan; ayyuan@aust.edu.cn
}

Received 29 August 2020; Revised 3 February 2021; Accepted 10 March 2021; Published 18 March 2021

Academic Editor: Zhijie Wen

Copyright (C) 2021 Anying Yuan et al. This is an open access article distributed under the Creative Commons Attribution License, which permits unrestricted use, distribution, and reproduction in any medium, provided the original work is properly cited.

\begin{abstract}
In recent years, with the increases in coal mining depths, the risk of coal seam outburst occurrences has increased. Therefore, it is of major significance to study the multiscale structures of soft and hard coal deposits in order to prevent and control the coal and gas outbursts. In this research investigation, soft and hard coal multiscale structures were comprehensively examined using various laboratory methods. The results revealed the following: (1) From a macrostructural aspect, the physical and mechanical properties of the soft coal were weaker than those of the hard coal. It was found that the majority of the examined specimens were characterized by scaly structures without blocks larger than $50 \mathrm{~mm}$. The hard coal was observed to be mainly massive with only a small part being clastic. Therefore, the structural characteristics were considered to be stable. (2) From a microstructural perspective, the surfaces of the soft coal specimens were observed to be rough. The pores were found to be more developed, with the edge of pores being mainly hackly. At the same time, fractures were also relatively developed, showing good connectivity. (3) From a micropore structural perspective, it was found that the BET-specific surface areas and BJH-specific surface areas of the soft coal specimens were higher than those of the hard coal specimens, which indicated that the gas adsorption and diffusion migration abilities of the soft coal were greater than those of the hard coal. (4) It was suggested from the study results that the ventilation and gas extraction processes should be strengthened in the mining activities of coal seams with high, soft stratification content. At the same time, the methods used for water injection modification should be enhanced in order to improve the mechanical stability of soft coal. Consequently, the instantaneous released gases will be decelerated, and the occurrences of coal and gas outburst events in mine working faces can be prevented.
\end{abstract}

\section{Introduction}

In recent years, the risks of outbursts in coal seams have increased with the increases in coal mining depths. It has been found that many shallow non-outburst coal seams have gradually transformed into outburst coal seams following the mining activities entering deeper levels. Outburst accidents have become the main factors which seriously endanger safe production activities in coal mines [1-4]. In order to effectively prevent and control such dynamic disasters as coal and gas outbursts, Chinese and international researchers have carried out many studies regarding coal outburst mechanisms using outburst case analyses, field investigations, laboratory simulations, and numerical calculations [5-10].
The phenomenon of soft stratification is known to exist in the majority of coal seams. The existence of soft stratification tends to increase the possibility of coal spalling. At the same time, the existence of soft stratification also tends to increase the uncertainties related to coal gas diffusion and migration processes [11-13]. Subsequently, it is of major significance to study the multiscale structural characteristics of soft coal and hard coal for the purpose of revealing the mechanisms of coal and gas outburst [14-16].

At the present time, the main methods of coal structure analysis include mercury intrusion methods, liquid nitrogen adsorption methods, $\mathrm{CO}_{2}$ adsorption methods, small-angle neutron scattering methods, and microscopy methods [17-20]. The main parameters characterizing pore structures 
include pore volumes, specific surface areas, fractal dimensions, equivalent pore radii, and porosity [21-23].

In the previous determinations of pore structures, both Chinese and international researchers have conducted a great deal of exploratory studies related to the differences in pore structures in different types of coal and the changes in adsorption and desorption performances caused by such differences [24-28]. At the present time, according to the available research literature, it is considered that the porosity and total pore volume of a coal body will increase as a result of structural deformations. For example, with the strengthening of structural deformations, the scale of influence on the pore structure deformations will tend to decrease from the large pores to the transition pores. Then, with increases in tectonic stress, the main damages will occur in the macropores. The characteristics of coal generally include pore structures which are favorable for gas adsorption. The adsorption performances of coal to gas will become weaker with increased crushing degrees. Also, it has been indicated that the inflection point of the low-temperature liquid nitrogen adsorption will be advanced following tectonic activities, with the coal tending to have smaller average pore sizes and higher adsorption pore volumes and pore-specific surface areas. Moreover, the adsorption capacity of the coal following increased tectonic activities has been found to be significantly higher than that of indigenous coal of the same coal grade [29-32].

Based on the above, domestic and foreign experts have done a lot of research on coal structure and gas adsorption and desorption and achieved fruitful results. However, the current research mainly adopts a single method to study a certain scale of coal body, lacking comprehensive comparative analysis. In this paper, the multiscale research method is used to comprehensively analyze the structural characteristics of coal and its influence on gas adsorption and desorption. This study mainly adopted an experimental method in order to comprehensively compare and analyze the macroscopic, mesoscopic, and microscopic multiscale structures of soft and hard coal in the No. 4 and No. 13 coal seams of a mine in the study area. The adopted method was able to successfully reveal the multiscale structures and gas adsorption and desorption characteristics of both soft and hard coal specimens. The research results obtained in this study were of major significance for the prevention and control of gas outburst disasters in the coal seams of stopes.

\section{Comparative Analyses of the Macrostructures of the Soft and Hard Coal}

2.1. Comparison of the Macrostructures between the Soft and Hard Coal. Figure 1 shows this study's comparison of the macrostructures of soft and hard coal specimens from the No. 4 and No. 13 coal seams of a mine in the study area. It can be seen from the figure that the hard coal bodies of the No. 4 and No. 13 coal seams were massive, with only a few considered to be clastic, showing stable structures and nonobvious joints. The soft coal in the No. 4 and No. 13 coal seams was characterized by loose and soft coal properties, disordered bedding, serious destruction of primary structures, and layered or lenticular distributions. Due to the nonequilibrium of the degrees of the stress, action range, and stress states, the coal seams' natural stratification with different ranges and thicknesses displayed various deformation characteristics, in which the original homogeneous and clear banded structures were lost, forming broken granular or pulverized coal.

\subsection{Particle Size Distribution Laws of the Soft and Hard Coal}

2.2.1. Particle Size Distribution Law of the Hard Coal. Table 1 and Figure 2 show the measured results of the particle size distributions of hard coal in the No. 4 and No. 13 coal seams. From the information shown in the figure and table, it can be concluded that the percentages of hard coal particles in the No. 4 and No. 13 coal seams had gradually decreased with the decreases in the particle sizes. That is to say, the content levels of the small-sized coal particles in the hard coal of the two coal seams were generally small. It was observed that the content levels of the smaller coal particles in the hard coal of No. 13 coal seam were higher than those in the No. 4 coal seam. The proportion of raw coal with particle sizes greater than $6 \mathrm{~mm}$ accounted for $92.57 \%$ of the hard coal in the No. 4 coal seam. It was found that, within that range, the granular coal with particle sizes ranging from $25 \mathrm{~mm}$ to $50 \mathrm{~mm}$ had the largest mass, accounting for $36.46 \%$. This was followed by the granular coal with particle sizes ranging between 13 and $25 \mathrm{~mm}$, which had accounted for $60.43 \%$ of the total mass. The proportion of the granular coal with particle sizes less than $6 \mathrm{~mm}$ accounted for $7.43 \%$. The proportion of raw coal with particle sizes more than $6 \mathrm{~mm}$ in the hard coal of the No. 13 coal seam was determined to be $62.99 \%$. In addition, within that range, the granular coal with particle sizes of more than $50 \mathrm{~mm}$ had the largest mass, accounting for $21.78 \%$. This was followed by the granular coal with particle sizes ranging between 25 and $50 \mathrm{~mm}$, which was observed to account for $37.09 \%$ of the total mass. The granular coal with particle sizes less than $6 \mathrm{~mm}$ accounted for $37 \%$ of the total mass.

2.2.2. Particle Size Distribution Law of the Soft Coal. Table 2 and Figure 3 show the measured results of the particle size distributions of the soft coal in the No. 4 and No. 13 coal seams. From the figure and table, it can be concluded that the percentages of the soft coal particles in the No. 4 and No. 13 coal seams had gradually increased with the decreases in the particle sizes. That is to say, the content levels of the small-sized coal particles in the hard coal of the two coal seams were quite high. The proportion of raw coal with particle sizes of more than $6 \mathrm{~mm}$ accounted for $48.98 \%$ of the soft coal of the No. 4 coal seam. It was observed that within that range, the granular coal with particle sizes ranging from $6 \mathrm{~mm}$ to $13 \mathrm{~mm}$ had the largest mass, accounting for $24.09 \%$. This was followed by the granular coal with particle sizes ranging between 3 and $6 \mathrm{~mm}$, which accounted for $21.93 \%$ of the total mass. The proportion of granular coal with particle sizes less than $6 \mathrm{~mm}$ accounted for $51.02 \%$. In addition, the 


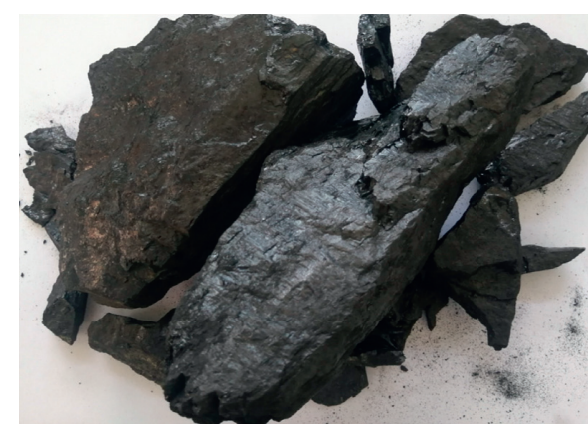

(a)

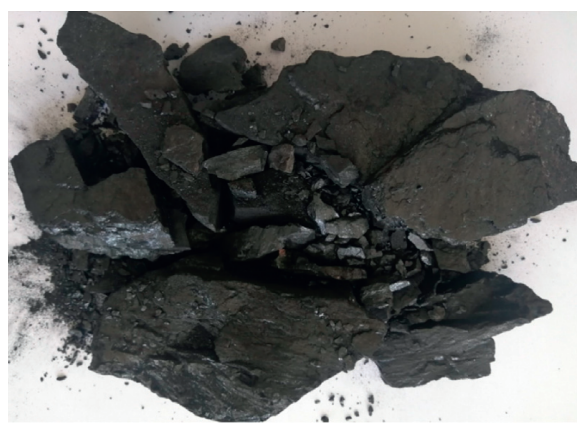

(c)

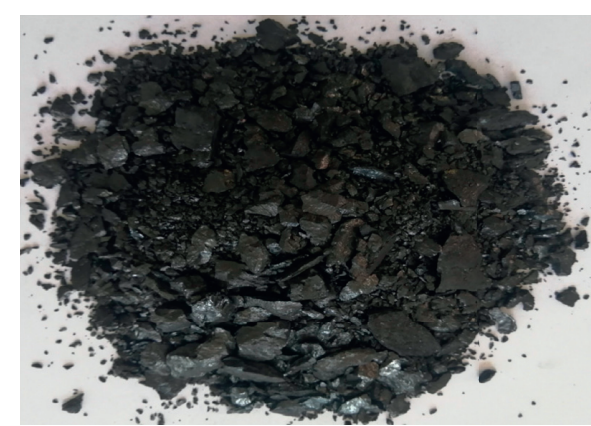

(b)

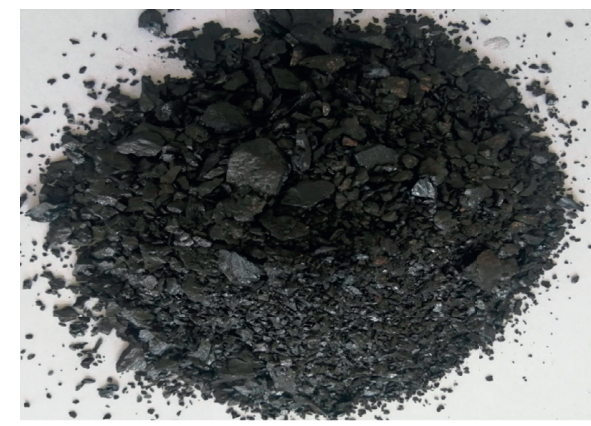

(d)

Figure 1: Macroscopic structures of the soft and hard coal in the different coal seams. (a) Hard coal of the No. 4 coal seam. (b) Soft coal in the No. 4 coal seam. (c) Hard coal of the No. 13 coal seam. (d) Soft coal in the No. 13 coal seam.

TABLE 1: Determination of the particle size distribution of the hard coal.

\begin{tabular}{lccc}
\hline \multicolumn{2}{c}{$\begin{array}{c}\text { No. } 4 \text { hard coal } \\
\text { Range of particle size }(\mathrm{mm})\end{array}$} & \multicolumn{2}{c}{$\begin{array}{c}\text { No. 13 hard coal } \\
\text { Mass percentage }(\%)\end{array}$} \\
\hline$>50$ & 16.56 & $25-50$ & 21.78 \\
$25-50$ & 36.46 & $13-25$ & 15.31 \\
$13-25$ & 23.97 & $6-13$ & 10.78 \\
$6-13$ & 15.58 & $3-6$ & 15.02 \\
$3-6$ & 4.60 & $2-3$ & 11.99 \\
$2-3$ & 0.80 & $1-2$ & 2.47 \\
$1-2$ & 0.98 & $0.5-1$ & 8.70 \\
$0.5-1$ & 0.52 & $0.25-0.5$ & 6.47 \\
$0.25-0.5$ & 0.27 & $0.125-0.25$ & 5.03 \\
$0.125-0.25$ & 0.15 & $0.075-0.125$ & 1.88 \\
$0.075-0.125$ & 0.11 & & 0.47 \\
\hline
\end{tabular}

proportion of raw coal with particle sizes more than $6 \mathrm{~mm}$ in the soft coal of the No. 13 coal seam was $36.88 \%$. It was found that, within that range, the granular coal with particle sizes between 3 and $6 \mathrm{~mm}$ had the largest mass, accounting for $24.16 \%$. The granular coal with particle sizes ranging between 6 and $13 \mathrm{~mm}$ accounted for $47.31 \%$ of the total mass, and the granular coal with particle sizes less than $6 \mathrm{~mm}$ accounted for $63.15 \%$ of the total mass.

It was determined in this study, based on the abovementioned analysis of the particle size distributions of soft and hard coal, that the particle sizes of the granular coal in the hard coal were generally larger, while the coal with particle sizes less than $6 \mathrm{~mm}$ accounted for only a small proportion. Furthermore, there were generally no granular coal particles observed which were larger than $50 \mathrm{~mm}$ in the soft coal, and the coal with particle sizes less than $6 \mathrm{~mm}$ accounted for a large proportion. This was found to be particularly true for the coal particles in the No. 13 coal seam, where the proportion of granular coal smaller than $6 \mathrm{~mm}$ reached $63.15 \%$.

\section{Comparative Analysis on the Mesostructures of the Soft and Hard Coal}

In the present study, in order to analyze the coal structures more comprehensively, the coal samples from the different coal seams were selected and scanned by SEM, with a magnification factor of approximately 1,000 times. Then, the obtained mesoscopic scanning results were compared and analyzed. 


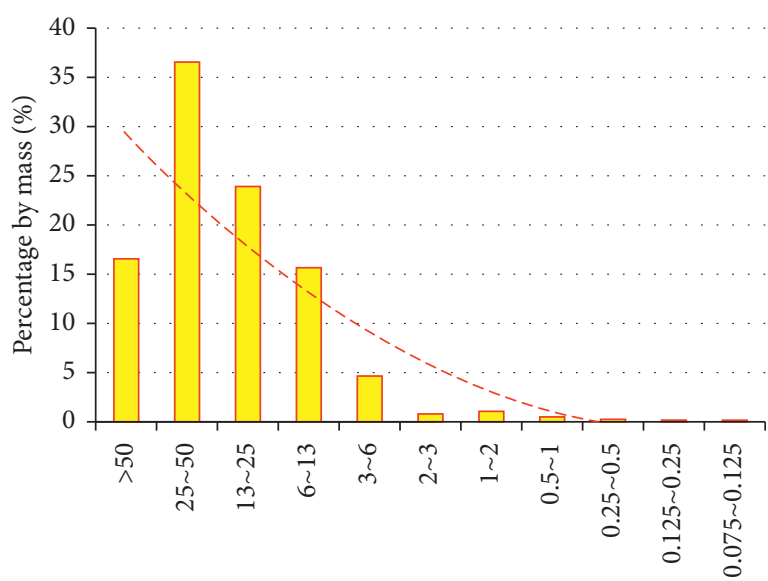

Particle size range $(\mathrm{mm})$

(a)

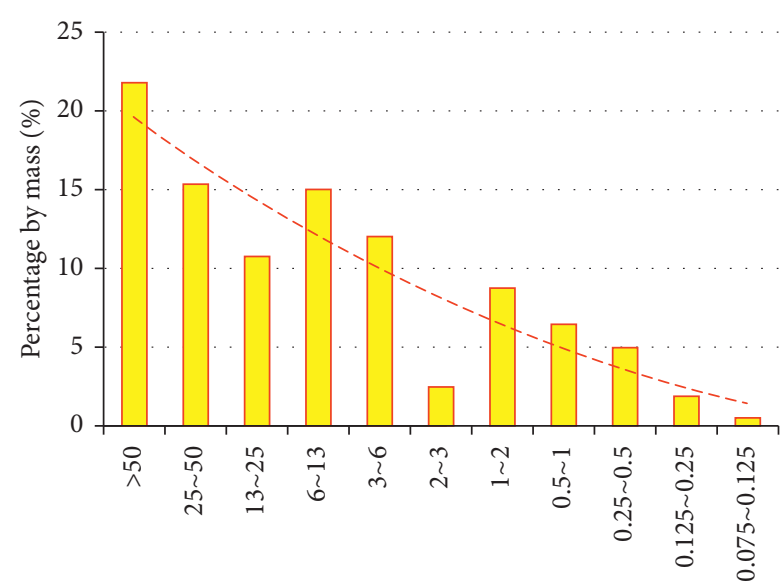

Particle size range $(\mathrm{mm})$

(b)

Figure 2: Distribution law of the particle sizes of the hard coal in the different coal seams. (a) Hard coal of the No. 4 coal seam. (b) Hard coal of the No. 13 coal seam.

TABle 2: Determination of particle size distributions of the soft coal.

\begin{tabular}{lccc}
\hline & No. 4 soft coal & \multicolumn{2}{c}{ No. 13 soft coal } \\
Range of particle size $(\mathrm{mm})$ & Mass percentage $(\%)$ & Range of particle size $(\mathrm{mm})$ & Mass percentage $(\%)$ \\
\hline$>50$ & 0.00 & $25-50$ & 0.00 \\
$25-50$ & 9.59 & $13-25$ & 1.85 \\
$13-25$ & 15.30 & $6-13$ & 23.15 \\
$6-13$ & 24.09 & $3-6$ & 24.16 \\
$3-6$ & 21.93 & $2-3$ & 5.32 \\
$2-3$ & 4.39 & $1-2$ & 12.10 \\
$1-2$ & 10.90 & $0.5-1$ & 10.82 \\
$0.5-1$ & 7.49 & $0.25-0.5$ & 7.32 \\
$0.25-0.5$ & 3.73 & $0.125-0.25$ & 2.74 \\
$0.125-0.25$ & 2.38 & $0.075-0.125$ & 0.69 \\
$0.075-0.125$ & 0.20 & & \\
\hline
\end{tabular}

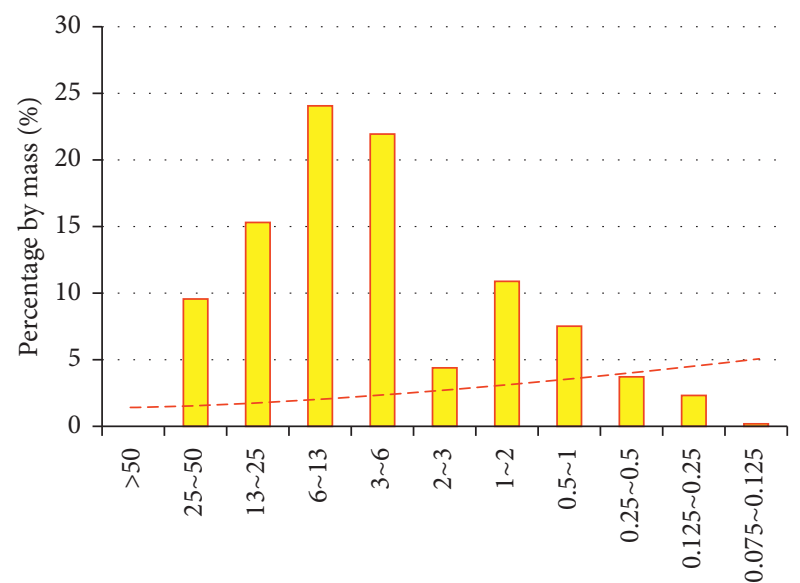

Percentage by mass (\%)

(a)

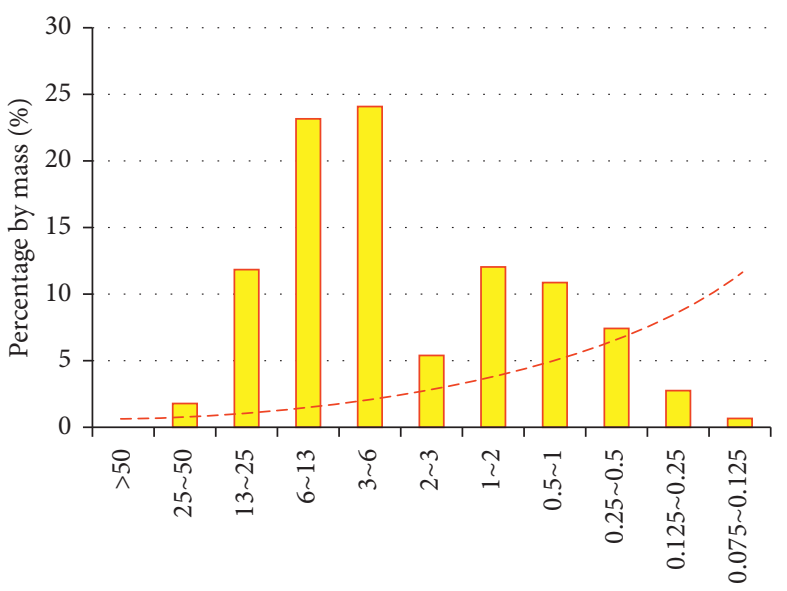

Particle size range $(\mathrm{mm})$

(b)

Figure 3: Distribution laws of the particle sizes of the soft coal in the different coal seams. (a) Soft coal in the No. 4 coal seam. (b) Soft coal in the No. 13 coal seam. 
3.1. Analysis on the Mesostructures of the Hard Coal. Figure 4 shows the microscopic scanning results of the hard coal specimens obtained from the No. 4 and No. 13 coal seams. It can be seen in the figure that the surfaces of the hard coal specimens were rough and characterized with attachments. The surfaces were mainly composed of thin mineral layers displaying grinding marks, local unevenness, and crumpled deformations. The small circular shearing fracture slip sheets were sparsely developed, which increased the area of gas adsorption. In addition, the pores were relatively developed, which provided favorable conditions for gas adsorption. However, the development of fractures was found to be general, resulting in only generalized gas desorption and diffusion conditions.

3.2. Analysis of the Mesostructures of the Soft Coal. Figures 5(a) and 5(b) show the microscanning results of the soft coal in the No. 4 coal seam. As can be seen in the figure, the surfaces of the soft coal in the No. 4 coal seam were relatively rough and uneven, and the pores were relatively developed. The edges of the pores were observed to be generally serrated. In addition, there were significant differences in pore sizes, ranging from several microns to tens of microns. It has been determined that the most direct influences on the development of pores in coal bodies located in the high-gas coal seams are the corresponding increases in gas adsorption capacity. Terraced fractures are generally characterized by many grinding marks and scaly structures, which greatly increases the surface areas of the coal bodies which come in contact with outside environments. At the same time, the grinding marks formed under the actions of tectonic compressive stress tend to lead to obvious the development of microcracks. As a result, with the good connectivity between pores, dominant channels for gas flow can be formed.

Figures 5(c) and 5(d) detail the microscopic scanning results of the soft coal in the No. 13 coal seam. It can be seen in the figures that the soft coal of the No. 13 coal seam was obviously layered and had large numbers of pores. In addition, the fracture development was obvious with the phenomena of crushing and running-through surrounding the fractures. The existence of a large number of pores provides favorable conditions for the attachment of gas, and the running-through of fractures provides superior channels for the flow and diffusion of the gas.

As mentioned above, the mesostructures of the soft coal were conducive to gas adsorption and desorption, and the soft coal gas desorption conditions were superior to those of the hard coal. Therefore, during mining activities, it is important that sufficient attention is given to the control of gas in the soft coal deposits of coal seam working faces.

\section{Comparative Analysis of the Micropore Structures of the Soft and Hard Coal}

In this paper, two expressions of specific surface area are mentioned, which are BET-specific surface area and $\mathrm{BJH}$-specific surface area. The BET-specific surface area mainly represents the pore surface area of coal and the pore surface area below the pore. Small holes and the holes below are mainly places for the occurrence of gas in coal body. The specific surface area of $\mathrm{BJH}$ mainly represents the surface area of mesopores and above. The holes above the middle hole mainly provide channels for gas migration and diffusion.

4.1. Analysis Results of the BET-Specific Surface Areas of the Soft and Hard Coal. This study's research results indicated that the micropores within coal bodies are the main spaces for gas adsorption. Therefore, the larger the BET-specific surface areas measured using the BET-specific surface area test method are, the higher the gas adsorption capacity will be, and vice versa.

In Table 3 and Figure 6, the BET-specific surface area measurement results of the No. 4 and No. 13 coal seams are detailed. It was concluded from the measurement results that the BET-specific surface areas of the different coal seams generally displayed obvious differences. The BET-specific surface areas of soft coal in each coal seam were observed to be greater than those of the hard coal, indicating that the soft coal in each coal seam had a higher adsorption capacity, and thereby larger gas adsorption amounts. Among those, the BET-specific surface areas of the soft and hard coal in the No. 13 coal seam were both large and found to be very similar. The BET-specific surface areas of the soft coal were slightly higher than that of the hard coal. Meanwhile, the BET-specific surface areas of the hard coal in the No. 4 coal seam were approximately 2.15 times of the soft coal.

\subsection{Analysis of BJH-Specific Surface Areas of the Soft and Hard} Coal. This study's analysis results revealed that the small pores in the coal mainly provided conditions for the capillary condensation, diffusion, and permeability of the gas. Therefore, the larger $\mathrm{BJH}$-specific surface areas measured using the $\mathrm{BJH}$-specific surface area test method in this study indicated stronger levels of capillary condensation, diffusion, and flow capacity for the gas, and vice versa.

Table 4 and Figure 7 show the measurement results of the BJH-specific surface areas of the No. 4 and No. 13 coal seams. As can be seen from the measurement results, the $\mathrm{BJH}$-specific surface areas of the different coal seams had displayed general obvious differences, and the $\mathrm{BJH}$-specific surface areas of the soft coal in the No. 4 and No. 13 coal seams were determined to be larger than those of the respective hard coal in the two coal seams. The $\mathrm{BJH}$-specific surface areas of the soft coal in each coal seam were approximately 1.43 to 1.94 times of those of the hard coal, which indicated that the soft coal of each coal seam was more favorable to gas diffusion. At the same time, the BJHspecific surface areas of the soft and hard coal in the No. 13 coal seam were greater than those in the No. 4 coal seam. Therefore, it was concluded in this study that the No. 13 coal seam was more conducive to gas diffusion and migration processes. 


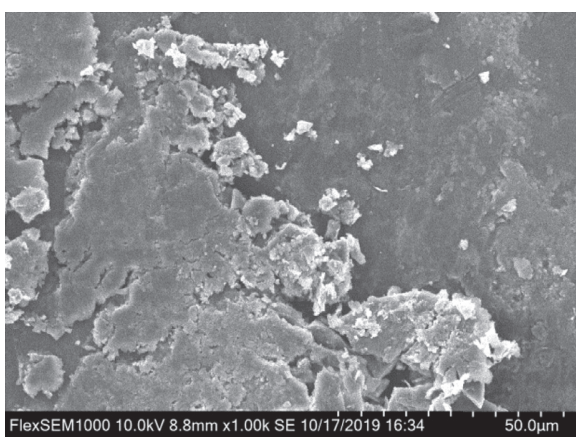

(a)

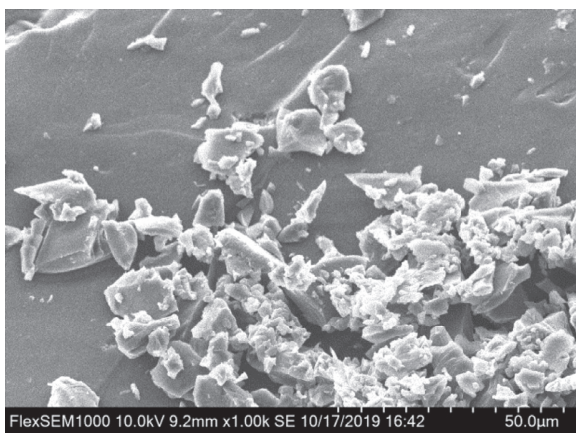

(c)

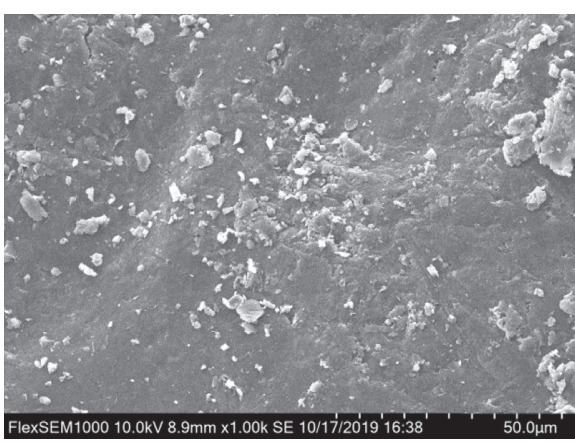

(b)

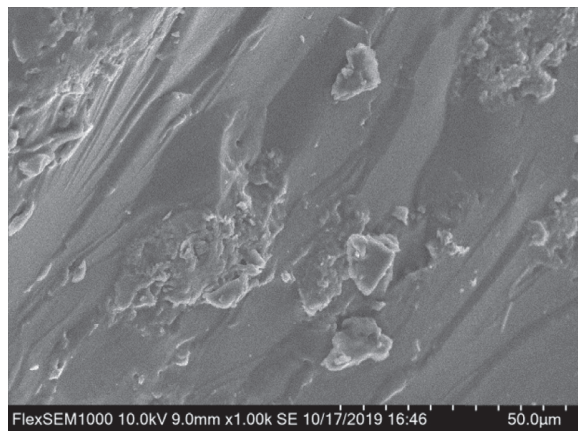

(d)

Figure 4: Mesostructures of the hard coal in the different coal seams. (a) No. 1 hard coal in the No. 4 coal seam. (b) No. 2 hard coal in No. 4 coal seam. (c) No. 1 hard coal in the No. 13 coal seam. (d) No. 2 hard coal in the No. 13 coal seam.

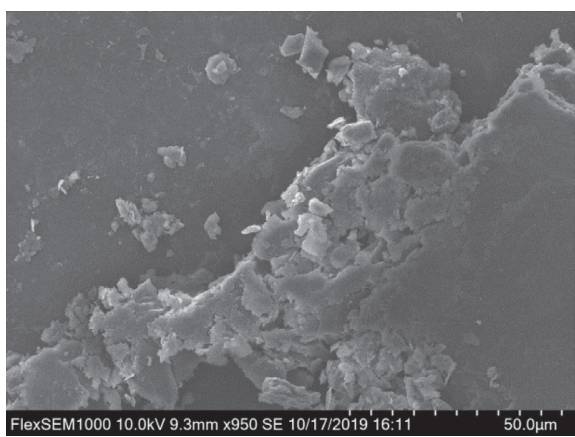

(a)

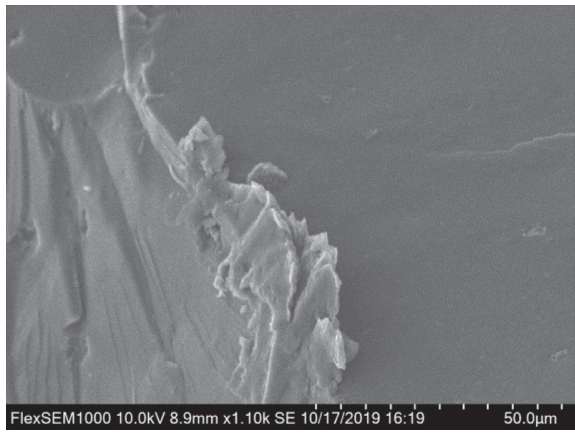

(c)

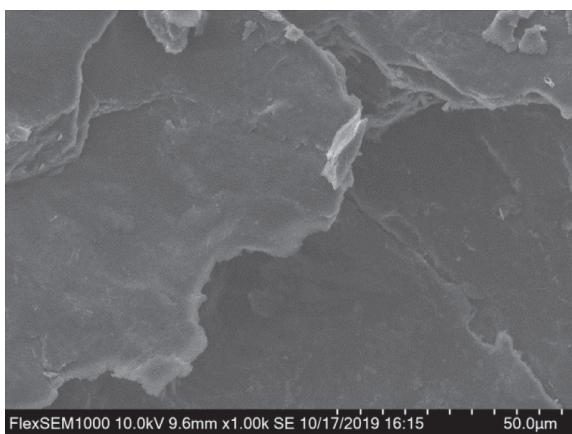

(b)

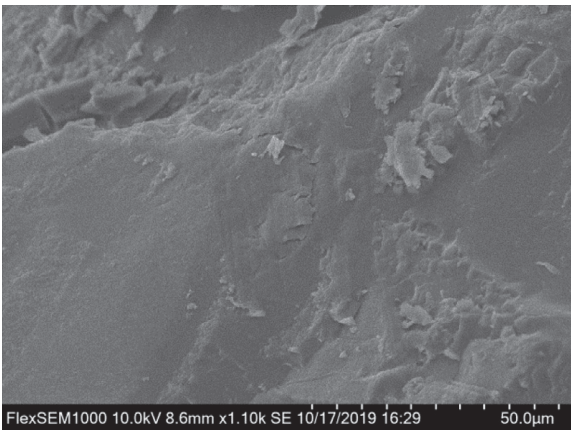

(d)

FIGURE 5: Mesostructures of the soft coal in the different coal seams. (a) No. 1 soft coal in the No. 4 coal seam. (b) No. 2 soft coal in the No. 4 coal seam. (c) No. 1 soft coal in the No. 13 coal seam. (d) No. 2 soft coal in the No. 13 coal seam. 
TABle 3: BET-specific surface areas of the different coal seams.

\begin{tabular}{lccccc}
\hline Pore structure parameters & No. & No. 4 hard coal & No. 4 soft coal & No. 13 hard coal & No. 13 soft coal \\
\hline & 1 & 0.5635 & 1.4695 & 2.0563 & 1.2967 \\
BET-specific surface area $\left(\mathrm{m}^{2} / \mathrm{g}\right)$ & 2 & 0.6875 & 1.3009 & 1.9152 & 2.1865 \\
& 3 & 0.7642 & 1.5750 & 1.2207 & 2.0363 \\
& Average & 0.6717 & 1.4485 & 1.7307 & 1.8398 \\
\hline
\end{tabular}

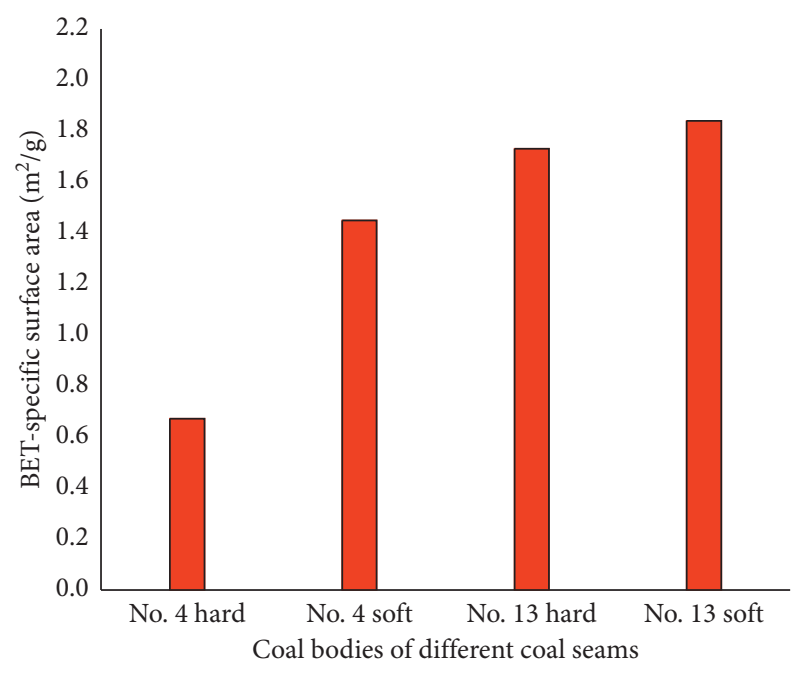

BET-specific surface area

FIGURE 6: BET-specific surface areas of the different coal seams.

TABle 4: BJH-specific surface areas of the different coal seams.

\begin{tabular}{lccccc}
\hline Pore structure parameters & No. & No. 4 hard coal & No. 4 soft coal & No. 13 hard coal & No. 13 soft coal \\
\hline & 1 & 0.3636 & 1.2447 & 1.3582 & 0.9928 \\
BJH-specific surface area $\left(\mathrm{m}^{2} / \mathrm{g}\right)$ & 2 & 0.6991 & 0.9693 & 1.0846 & 1.6659 \\
& 3 & 0.7318 & 1.2734 & 0.4973 & 1.5730 \\
& Average & 0.5982 & 1.1625 & 0.9800 & 1.4106 \\
\hline
\end{tabular}

\section{Pore Shape Distribution Characteristics of the Soft and Hard Coal}

In the present study, in accordance with the hysteresis loop type of adsorption isotherm presented in previous related study results, the pores were divided into the following: cylindrical types $(\mathrm{A})$; slit types $(\mathrm{B})$; wedge types $(\mathrm{C}, \mathrm{D})$; and ink bottle types (E), as shown in Figure 8 [33]. Then, based on the connectivity of the pores, the types of pores in the coal were also be divided into the following groups: connected pores; internal connected pores; dead-end pores; and closed pores. The first three types were referred to as open pores due to their good connectivity, which was found to have major impacts on the adsorption, desorption, and diffusion of the coal gas. The fourth type was more conducive to the occurrence of gas.

It was found that by comparing and analyzing the liquid nitrogen adsorption isotherms of the coal samples from the different coal seams, and according to the classification and description of the hysteresis loop types of adsorption isotherms shown in Figure 8, it could be concluded that the adsorption isotherms and desorption isotherms of the soft coal of the No. 4 coal seam, hard coal of the No. 13 coal seam, and the soft coal of the No. 13 coal seam were not completely coincident. Moreover, the adsorption and desorption curves had basically coincided in the higher and lower relative pressure sections, which indicated that there were a large number of open pores and semiclosed pores in those coal samples. The desorption curves showed that the adsorbate occurred as a phenomenon of capillary condensation, and the hysteresis loop of the adsorption loop occurred in the sections with relative pressure levels ranging between 0.5 and 1.0. These findings indicated that there were a variety of pores in those pressure sections, including cylindrical pores with openings at both ends, narrow slits with openings on all sides, and so on. These types of pores were considered to be conducive to the diffusion and migration of the coal gas. The adsorption and desorption isotherms of the hard coal in the No. 4 coal seam displayed obvious inflection points when the relative pressure was approximately 0.5 . This indicated that the corresponding pores at the inflection points in the coal samples were ink bottle type pores, and the corresponding pores at the left side of the inflection points were mainly semiclosed wedge pores and cylindrical pores. The shapes of the abovementioned types of pores were considered to be more favorable to gas 


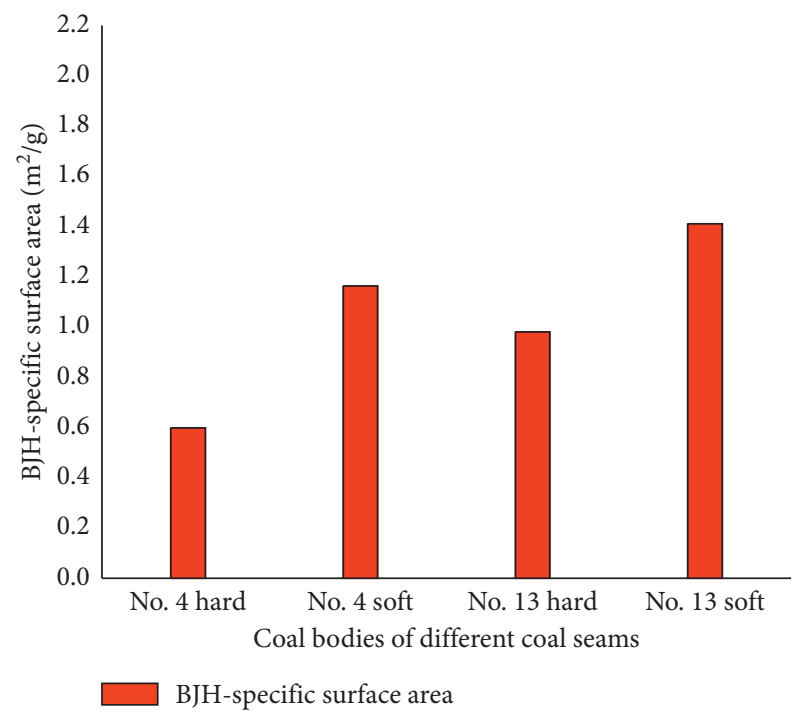

FiguRE 7: BJH-specific surface areas of the different coal seams.

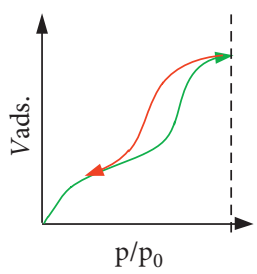

(a)

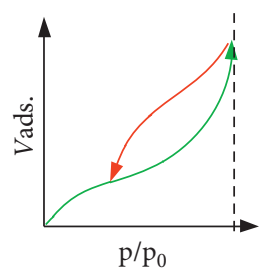

(b)

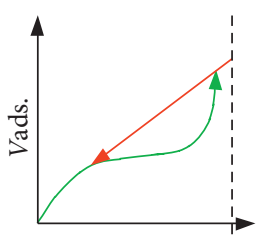

$\mathrm{p} / \mathrm{p}_{0}$

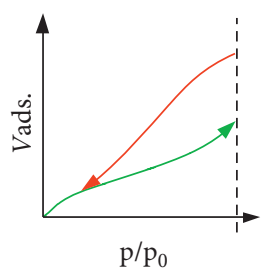

(d)

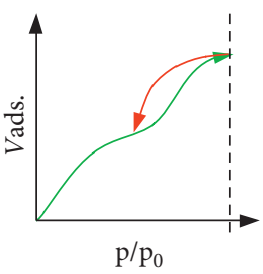

(e)

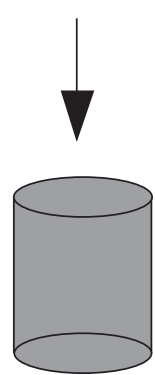

Cylindric

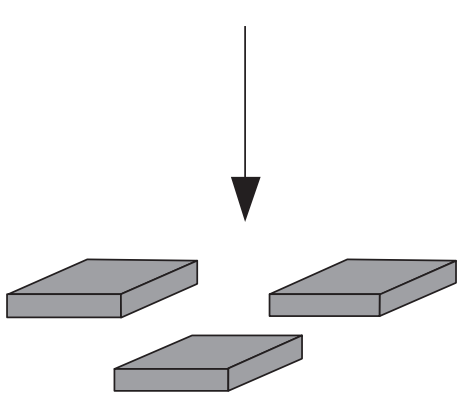

Slit shape

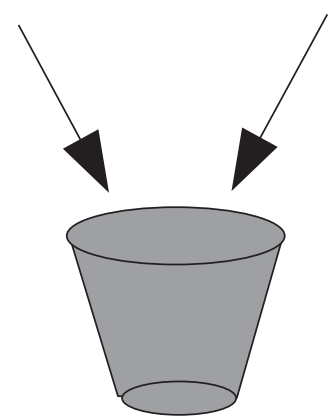

Slit shape

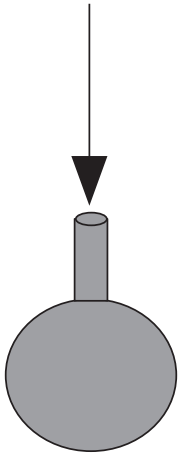

Slit shape

Figure 8: Hysteresis loop and its corresponding pore shape.

occurrence. However, they were not considered favorable for gas diffusion and migration processes, as shown in Figure 9.

According to the statistics of the maximum adsorption capacities of low-temperature liquid nitrogen adsorption in the examined coal samples, it was found that there were significant differences in the adsorption capacities of the coal samples from the different coal seams. The maximum adsorption capacity of the hard coal from the No. 4 coal seam was determined to be $0.95 \mathrm{~cm}^{3} / \mathrm{g}$ : that of the soft coal from the No. 4 coal seam was $2.48 \mathrm{~cm}^{3} / \mathrm{g}$; that of the hard coal of the No. 13 coal seam was $0.98 \mathrm{~cm}^{3} / \mathrm{g}$; and that of the soft coal from the No. 13 coal seam was $3.81 \mathrm{~cm}^{3} / \mathrm{g}$. It can be seen from the aforementioned results that the liquid nitrogen adsorption capacity of the hard coal in the No. 13 coal seam was the largest, and the maximum adsorption capacity of its soft coal was also significantly higher than that of the soft coal in the No. 4 coal seam. These findings suggested that there were more micropores in the hard coal and soft coal of the No. 13 coal seam. At the same time, it was also determined in this study through comparative analysis that the maximum adsorption capacity of the soft coal in each coal seam was significantly higher than that of the hard coal, indicating that there were more micropores in the soft coal of the two examined coal seams.

\section{Discussion}

In accordance with the abovementioned multiscale structure analysis results of the examined soft and hard coal specimens, the following determinations were made: 


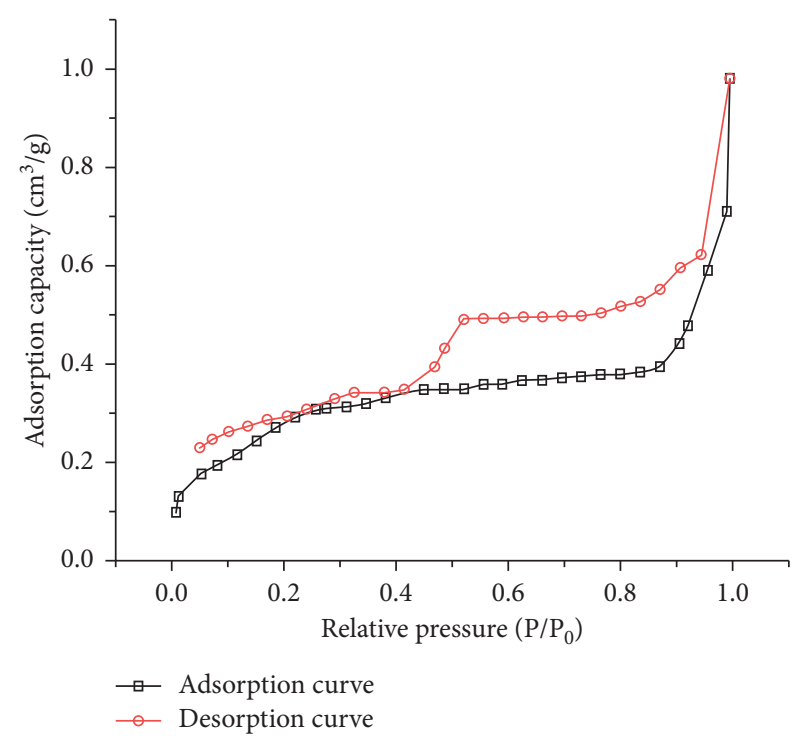

(a)

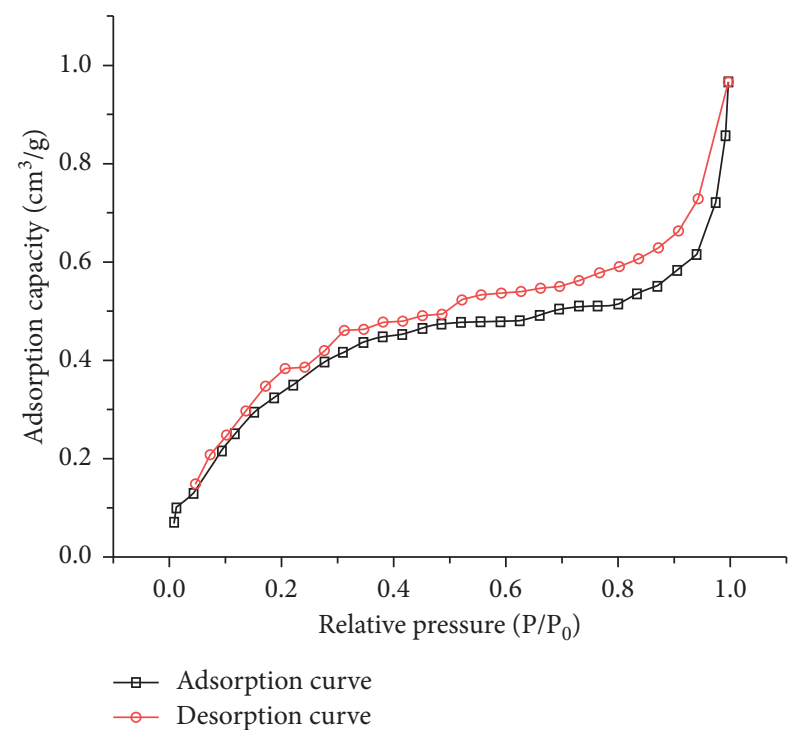

(c)

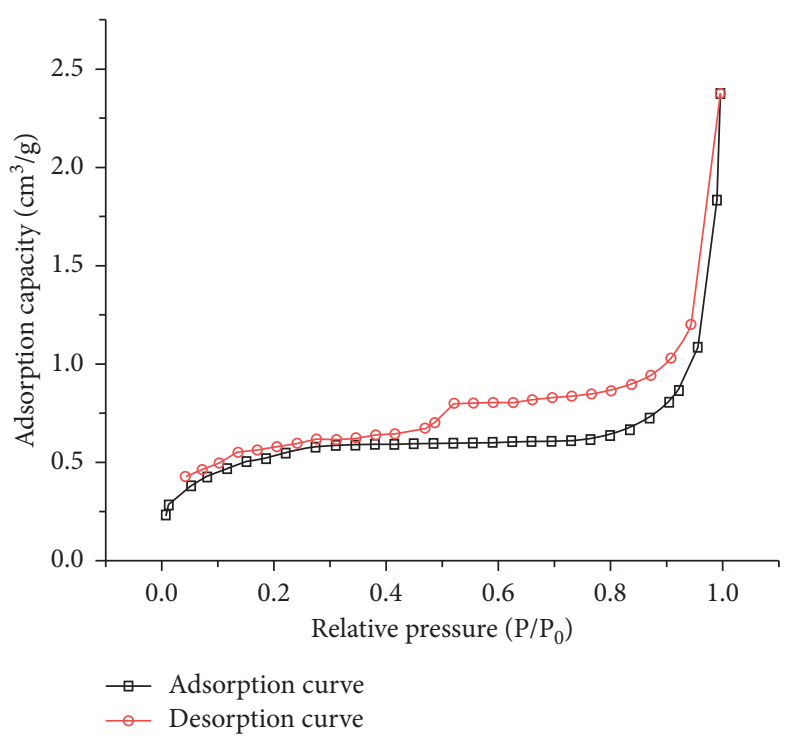

(b)

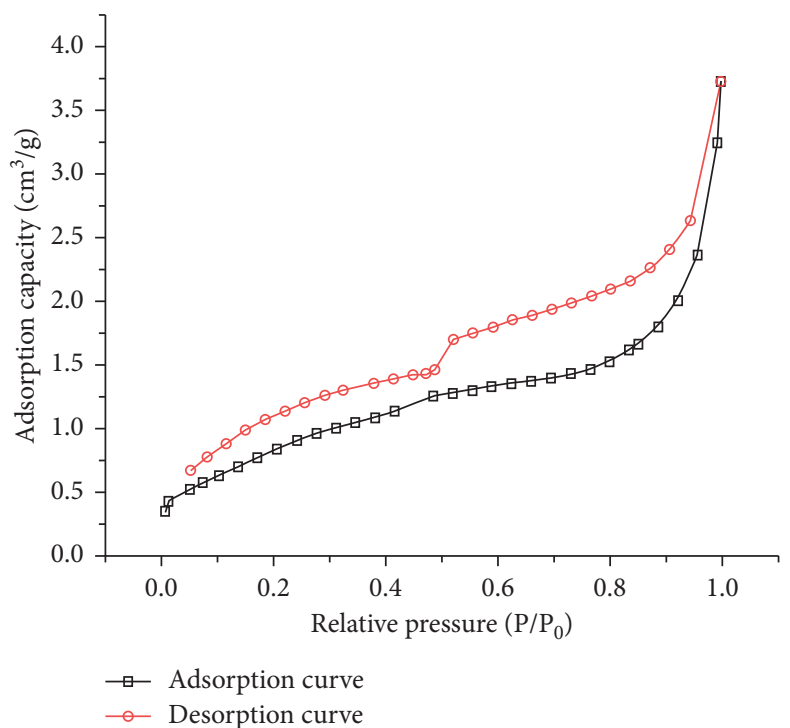

(d)

Figure 9: Low-temperature nitrogen adsorption and desorption curves of the coal samples in each coal seam. (a) No. 4 hard coal. (b) No. 4 soft coal. (c) No. 13 hard coal. (d) No. 13 soft coal.

(1) Macrostructural Aspect. Due to the nonequilibrium of the levels of the stress, action ranges, and stress states, the natural stratification with different ranges and thicknesses in the coal seams had become deformed, and the original homogeneous and clear banding structures had been lost. The physical and mechanical properties of the soft coal specimens were observed to be weaker than those of the hard coal specimens, and the majority were characterized by scaly structures without blocks larger than $50 \mathrm{~mm}$. Meanwhile, the properties of the hard coal included mainly block shapes, with only a small part being clastic, which indicated a generally stable structure.

(2) Mesostructural Aspect. The surfaces of the soft coal were observed to be rough, and the pores were more developed, with the edges of pores being mainly hackly. At the same time, the fractures were also relatively developed, showing good connectivity. Generally speaking, the mesostructures of the soft coal were conducive to gas adsorption and desorption, and its gas desorption conditions are found to be superior to those of the hard coal. Therefore, it is recommended in this study that adequate attention be paid to gas control measures in the soft coal deposits of coal seam working faces.

(3) Micropore Structural Aspect. The BET-specific surface areas and BJH-specific surface areas of the soft coal were determined to be higher than those of the hard coal. These findings indicated that the gas 
adsorption and diffusion migration ability of the soft coal were higher than those of the hard coal.

According to this study's multiscale structure analysis results of the soft and hard coal specimens examined from the study area, it was suggested that ventilation and gas extraction should be strengthened in the mining processes in coal seams with large soft stratification content levels. At the same time, water injection modification methods should be implemented in order to improve the mechanical stability of the soft coal deposits in order to slow down the instantaneous gas release abilities and prevent the occurrences of coal and gas outburst accidents in those types of working faces.

\section{Conclusions}

In this paper, the multiscale structure of soft coal and hard coal is studied, respectively, by laboratory experiment and theoretical analysis. The root cause of various structural differences of soft coal and hard coal is revealed, and the prevention and control methods of coal and gas outburst are proposed. The research results have important guiding significance and application value for the gas control of medium- and high-gas seam in coal mine site. The following main conclusions were obtained in this study:

(1) The physical and mechanical properties of the soft coal were observed to be weaker than those of the hard coal, with the majority displaying the characteristics of scaly structures without blocks larger than $50 \mathrm{~mm}$. Meanwhile, the hard coal was observed to be mainly block shaped with only a small portion clastic shaped, which indicated that the hard coal had a stable structure.

(2) According to the mesoscopic scanning results, it was determined that the surfaces of the soft coal were rough with more developed pores, and the edges of the pores were generally hackly. At the same time, the fractures were also relatively developed, showing good connectivity. Generally speaking, the mesostructures of the soft coal were conducive to gas adsorption and desorption, and the soft coal's gas desorption conditions were better when compared with the hard coal. Therefore, in future mining activities, sufficient attention should be given to gas control measures in the soft coal areas of coal seam working faces.

(3) It was determined that according to this study's analysis of the micropore structures of the soft and hard coal specimens, the BET-specific surface areas and BJH-specific surface areas of the soft coal were higher than those of the hard coal, which indicated that the gas adsorption and diffusion migration abilities of the soft coal were more effective than those of the hard coal.

(4) The results obtained in this study suggested that ventilation and gas extraction processes should be strengthened when mining coal seams with large soft stratification content levels. At the same time, the implementation of water injection modification methods would be useful for improving the mechanical stability of soft coal deposits. Subsequently, the instantaneous release of gas could be slowed down in order to prevent the occurrences of coal and gas outburst accidents in working faces.

\section{Data Availability}

The data used to support the findings of this study are included within the article.

\section{Conflicts of Interest}

The authors declare that there are no conflicts of interest regarding the publication of this paper.

\section{Acknowledgments}

This research was funded by the Natural Science Foundation of Anhui Province (no. 1908085QE226), Independent Project of State Key Laboratory of Mining-Induced Response and Disaster Prevention and Control in Deep Coal Mines (SKLMRDPC19ZZ02), Open Project of State Key Laboratory of Mining-Induced Response and Disaster Prevention and Control in Deep Coal Mines (SKLMRDPC19KF03), National Natural Science Foundation of China (51874006 and 51974008), and Science Research Foundation for Young Teachers of Anhui University of Science and Technology (no. QN2018117).

\section{References}

[1] E. Bai, W. Guo, Y. Tan, and D. Yang, "The analysis and application of granular backfill material to reduce surface subsidence in China's northwest coal mining area," Plos One, vol. 13, no. 7, Article ID e0201112, 2018.

[2] Q. Huang and D. U. Junwu, "Coupling control of pillar stress and surface cracks in shallow coal seam group mining," Journal of China Coal Society, vol. 43, no. 3, pp. 591-59, 2018.

[3] Y. U. Bin, "Structural evolution of breaking roof group of multiple coal seams and its influence on lower coal seam mining," Journal of China Coal Society, vol. 40, pp. 261-266, 2015.

[4] X. Yang, G. Wen, L. Dai, H. Sun, and X. Li, "Ground subsidence and surface cracks evolution from shallow-buried close-distance multi-seam mining: a case study in bulianta coal mine," Rock Mechanics and Rock Engineering, vol. 52, pp. 2835-2852, 2019.

[5] G. Haijun, Y. Liang, C. Yuanping et al., "Effect of moisture on the desorption and unsteady-state diffusion properties of gas in low-rank coal," Journal of Natural Gas Science and Engineering, vol. 57, pp. 45-51, 2018.

[6] M.-Y. Chen, Y.-P. Cheng, J.-C. Wang, H.-R. Li, and N. Wang, "Experimental investigation on the mechanical characteristics of gas-bearing coal considering the impact of moisture," Arabian Journal of Geosciences, vol. 12, no. 18, p. 571, 2019.

[7] B. Zhao, G. Wen, H. Sun et al., "Similarity criteria and coallike material in coal and gas outburst physical simulation," International Journal of Coal Science \& Technology, vol. 5, no. 2, pp. 167-178, 2018. 
[8] S. Xue, L. Yuan, J. Wang, Y. Wang, and J. Xie, "A coupled DEM and LBM model for simulation of outbursts of coal and gas," International Journal of Coal Science \& Technology, vol. 1, no. 2, pp. 22-29, 2015.

[9] Z. Huijie, Z. Lang, W. Dong et al., "Gas emission characteristics of tectonic coal and microscopic explanation of pore structure," Journal of China Coal Society, vol. 3, no. 12, pp. 3404-3410, 2018.

[10] Y. Liu and L. Mingju, "Effect of particle size on difference of gas desorption and diffusion between soft coal and hard coal," Journal of China Coal Society, vol. 40, no. 3, pp. 579-587, 2015.

[11] H. Qin, J. Wei, and S. Li, "Analysis of the coal seam spalling-failure mechanism based on the seepage instability theory," PLoS One, vol. 14, no. 7, Article ID e0219735, 2019.

[12] B. Song, S. Zhang, D. Zhang et al., "Inorganic cement grouting for reinforcing triangular zone of highly gassy coal face with large mining height," Energies, vol. 11, no. 10, 2018.

[13] R. Gao, T. Kuang, and Y. Lan, "The mechanism and control technology of strong strata behavior in extra-thick coal seam mining influenced by overlying coal pillar," Open Geosciences, vol. 11, pp. 452-461, 2019.

[14] D. Kong, Y. Liu, and S. Zheng, "Sensitivity analysis of influencing factors and control technology for coalface failure," Arabian Journal of Geosciences, vol. 12, p. 550, 2019.

[15] Q. Hengjie, W. Chunguang, and L. I. Sen, "Analysis of coal seam spalling fracture mechanism based on theory of seepage and loss stability," Safety in Coal Mines, vol. 11, pp. 175-179, 2019.

[16] Z. Shu-Tong, Y. Zhi-Heng, W. Hua-Jun, and X. U. Hong-Liang, "Seepage law of grouting for reinforcing fractured coal in mining face," Journal of Mining \& Safety Engineering, vol. 23, no. 3, pp. 359-361, 2006.

[17] D. M. Guo, Y. Zhang, P. F. Han, and J. Z. Zhuang, "Physical model test on thick gravel layer inclined shaft deformation and failure in yili no. 1 coal mine," Advanced Materials Research, vol. 255-260, pp. 3827-3831, 2011.

[18] Z. Zhaozhao, P. Jienan, L. I. Meng, and W. Kai, “Total pore structure characteristics of coal with different metamorphic degree based on joint experiment of mercury intrusion and low temperature nitrogen adsorption," Safety in Coal Mines, vol. 49 , no. 4 , pp. 25-29, 2018.

[19] B. Gong, Y. Jiang, and L. Chen, "Feasibility investigation of the mechanical behavior of methane hydrate-bearing specimens using the multiple failure method," Journal of Natural Gas Science and Engineering, vol. 69, Article ID 102915, 2019.

[20] F. Xianglong, C. Yidong, L. Dameng, and Z. Yingfang, "A mercury intrusion porosimetry method for methane diffusivity and permeability evaluation in coals: a comparative analysis," Applied Sciences, vol. 8, no. 6, p. 860, 2018.

[21] H. Zhang, L. Zhang, D. Wang, and J. Hou, "Gas emission characteristics of tectonic coal and microscopic explanation of pore structure," Mtan Xuebao/Journal of the China Coal Society, vol. 43, no. 12, pp. 3404-3410, 2018.

[22] Z. Chunwang, L. I. Shaoquan, and G. University, "Pore structure and gas adsorption characteristics of coal with low permeability," Safety in Coal Mines, vol. 1, 2019.

[23] S. Zhang, S. Tang, J. Zhang, and Z. Pan, "Pore structure characteristics of China sapropelic coal and their development influence factors," Journal of Natural Gas Science and Engineering, vol. 53, pp. 370-384, 2018.

[24] W. Li, Z. Liu, E. Su, and Y. Cheng, "Experimental investigation on the effects of supercritical carbon dioxide on coal permeability: implication for co_2 injection method," Energy \& Fuels, vol. 33, no. 1, pp. 503-512, 2019.
[25] Y. Yang, J. Liu, J. Wang, J. Cheng, Z. Wang, and K. Cen, "Effect of the pyrolysis temperature on the grindability of semi-cokes produced by two kinds of low-rank coals," Energy \& Fuels, vol. 32, no. 2, pp. 1297-1308, 2018.

[26] Z. Li, D. Liu, Y. Cai, G. Si, and Y. Wang, "Pore structure and compressibility characteristics of heat treated coals by $\mathrm{n} 2$ adsorption/desorption and mercury intrusion porosimetry," Energy \& Fuels, vol. 34, no. 3, pp. 3173-3187, 2020.

[27] S. S. Raza, L. Ge, T. E. Rufford, Z. Chen, and V. Rudolph, "Anisotropic coal permeability estimation by determining cleat compressibility using mercury intrusion porosimetry and stress-strain measurements," International Journal of Coal Geology, vol. 205, pp. 75-86, 2019.

[28] Z. Liu, H. Yang, W. Wang, W. Cheng, and L. Xin, "Experimental study on the pore structure fractals and seepage characteristics of a coal sample around a borehole in coal seam water infusion," Transport in Porous Media, vol. 125, no. 2, pp. 1-21, 2018.

[29] S. Tao, S. Chen, D. Tang, X. Zhao, H. Xu, and S. Li, "Material composition, pore structure and adsorption capacity of low-rank coals around the first coalification jump: a case of eastern junggar basin, China," Fuel, vol. 211, no. 1, pp. 804-815, 2018.

[30] L. Zhenjian, Z. Zhenyu, C. Sing, and L. Yiyu, "Surface properties and pore structure of anthracite, bituminous coal and lignite," Energies, vol. 11, no. 6, pp. 1-14, 2018.

[31] C. Run, Q. Yong, Z. Pengfei, and W. Youyang, "Changes in pore structure of coal caused by cs 2 treatment and its methane adsorption response," Geofluids, vol. 2018, Article ID 7578967, 11 pages, 2018.

[32] A. Yuan, "A study of the differences in the gas diffusion and migration characteristics of soft and hard coal in high gas coal seams," Advances in Civil Engineering, vol. 2020, Article ID 8825625, 10 pages, 2020.

[33] X. J. Zhao, S. Yong, C. Chau et al., "Evolution law of pore characteristics of coal mass caused by cyclic liquid $\mathrm{CO}_{2}$ based on low-field nuclear magnetic resonance technology," Journal of China Coal Society, vol. 1-12, 2021. 